\title{
LVI. “Della Purificazione del Mercurio Memoria del Sig. Dott. G. Branchi," \&c. - Memoir on the purification of mercury
}

\section{Dr. Joseph Branchi}

To cite this article: Dr. Joseph Branchi (1817) LVI. “Della Purificazione del Mercurio Memoria del Sig. Dott. G. Branchi," \&c. - Memoir on the purification of mercury , Philosophical Magazine Series 1, 50:235, 348-353, DOI: 10.1080/14786441708637791

To link to this article: http://dx.doi.org/10.1080/14786441708637791

电 Published online: 27 Jul 2009.

Submit your article to this journal $\pi$

Џll Article views: 2

Q View related articles $\sqsubset$ 


\section{Description of the Plate.}

Fig. 1. is the germ of a gourd when the flower and seedvessels are first beginning to form.

Fig. 2. is the mechanism belonging to every single seed or grain of wheat, and intended to furnish nutriment to the seed both from the earth and atmosphere : but this curious display belongs to the atmosphere principally. $(a)$ is the heat of the grain when it first enters the almost empty bag of the seed $b, b, b$, which is now only inflated with air. The feather oo conveys the pollen to fructify the seed, and then takes with the hairs $b 6 b$ the nutriment from the atmosphere, while the vessels $d d d$ afterwards supply the powdered nutriment from the root.

Fig. 3. is a specimen of the gourd (before the flower passes off) cut horizontally, to show how the nutriment is principally taken in from the root and pours up the vessels (formed for the time) in the pith, and thrown into the seed-vessels by means of the pipes $c c c$, which are seen to give a fine powder, and thus fill each seci-vessel :-cut them which way you will, they equally yield the same picture.

Fig. 5. is the natural size of the wheat seed, when beginning : it is of no use to try it when older, the process is then over:- when once the seed is ready for the earth, a new process begins : all then is forming for the new embryo, which is indeed even at this time preparing in the heart of the seed. But I thought it would make a confusion to show its curious mechanism here.

Fig. 1. shows the gourd cut perpendicularly, with the seeds properly placed, receiving the juices of the atmosphere.

LVI. "Della Purificazione del Mercurio Memoria del Sig. Dott. G.Branchi," $\$$ c.-Memoir on the Purification of Mercury. By Dr.Joseph Branch!, Public Professor of Chemistry in the University of Pisa, Corresponding Member of the Royal Acadcmy of Science of Pistoja, \&o".*

I H periments in chemistry or physics, in consequence of being mixed with various metals, particularly lead and bismuth. In this state of adulteration its lustre soon tarnishes; it weighs lighter than when pure; leaves a blackish spot when poured on an earthen plate; divides into drops which though roundish are generally more or less compressed, and have an appendage or kind of tail; and on being exposed to the action of the fire immediately abandons the metals with which it was amalgamated.

Distillation is the known and generally-practised method of

* From the forthcoming Memoirs of the Pisa Academy. 
purlfying mercury in the state here described. Nevertheless Messrs.Guyton*, Brugnatelli $\uparrow$, Virey $\downarrow$, and other chemists, have justly observed, that in this operation a small part of the fixed metals rises with the mercury in the state of vapour; and MM. Klaproth and Wolff $\S$ assert, that it is extremely difficult by this means to separate all the bismuth. The iron filings which, according to Nollet, ought to be put into the retort over the mercury to be refined, in order that when the metal rises in vapour it inust pass between the particles of iron, assuredly do not contribute to produce a better result; and in fact, no modern author whose works I have been able to consult, recommends the above addition to the process. The continued agitation of this mercury in contact with the air was announced by Priestley as capable of purifying it. If (said he) it is a long time agitated in a stopped decanter of whose eapacity it does not occupy above a fourth part, and the air in the decanter be repeatedly renewed by means of bellows, the foreign metal will be converted into oxide, and the mercury become so pure as to resist all proof of extraneous matter by distillation. Nicholson, who said that he had repeated this method with success, recommended it to mathematical-instrument-makers, who had not the necessary apparatus for distillation. But Guyton with some very just observations dissents from this, and is of opinion that the adulterated mercury cannot by such means be liberated from all extraneous matter $\|$.

In the year 1798, considering that at the temperature of the atmosphere, some acids, as for example the sulphuric, do not dissolve mercury, although they unite with more or less facility to the above-mentioned metals, it occurred to me that it might be practicable to purify adulterated mercury by immersing it in one of these acids and repeatedly changing its surface. The result obtained by this kind of parting having answered my expectations, I have always used the same method on sneceeding occasions, and it is well known to many persons, who at my suggestion have put it in practice. Nevertheless I do not pretend that by such a process this mercury becomes perfectly pure, but only in a state fit for use in a great number of experiments. The most pure is justly considered by chemists as solely that which is separated from cinnabar by the united action of caloric and iron filings, or that which by the effect of caloric alone is obtained from what is called red precipitate--that is, the red oxide of mercury, by means of nitric acid 9 .

* Ansales de Chimie, xxv. 79.

+ Trattato Elementaire di Chimica Generale, iii. 136. $\ddagger$ Traité de Pharmacie, ii. 356 .

\$ Dizionario di Chimica del Sig. Prof. MoretTr, iij, 93, 101. II Annales de Chimie, xxr. 77. Thus silver of cupellation is pure ; but the purest is that which is obtained by the decomposition of muriate of silver. 
Neither do I pretend that the method of which I speak is positively new; perhaps it may be known, and probably othex artificers for private interest have kept it secret*. But as I have not seen it noticed in any book, 1 have thonght it proper to describe briefly the experiments which I have made on this subject, from which at least it may be more generally known that by means of some acids, the mercury of commerce may be purified sufficiently to serve in a great number of experiments not only in general physics, but also in chemistryt.

1 put in different vessels the quantity of three pounds in each; over one I poured a sufficient portion of strong vinegar, and over the other diluted sulphuric acid. By agitating and often shaking the vessels the mercury divided into small globules, and presented more points of contact to the acids; and I observed that they became turbid, and that with reagents they indicated having metallic matter in solution. Continuing the purification and renewing the quantity of acids, on the fourth day I separated the mercury from them, and after washing, drying, and passing it through a hole made with a pin in the bottom of a fummel of writing-paper, I placed it in different vessels. The mercury purified in this manner had a bright surface even after the space of several days.

This result encouraged me to try directly the same process on the adulterated mercury of commerce; and I made the experiment with success. I purified a great deal at different times, preferring however the diluted sulphuric to the acetic acid, because it may be used even still stronger, and it has a more powerful action on the extraneous metals. Such an operation, in which the sulphuric acid may be renewed a greater or lesser number of times, succeeds in a longer or shorter period; but it is not considered as terminated until the mercury divides, and continues for a considerable time in very minute globules, and without altering the acid, which must retain its transparency, and evince no trace of any metallic substance by reagents. In March 1813 I distilled in an earthen retort about seventeen pounds of mercury, which I used for various experiments, and which contained much lead and tin. Although it had abandoned an abumdant share of these metals, yet by the pellicle on its surface it was evident that it still contained much amalgam, an effect to which the still had

* In 1806, my friend and colleague Sign. Savi, then Professor of Experimental Philosophy (now Professor of Botany, and the unassuming author of several valuable tracts on the indigenous plants and forest and other trees of Tuscany), observed that a Milanese barometer-maker, purified his mepcury by means of a fluid, the nature of which he studiously concealed.

$\uparrow$ My assistant in the laboratory annually constructs mary barometers and thermometers, and he finds that mercury purified in this manner is of grẹat advantage. 
perhaps somewhat contributed, from its being so little curved that some particles might escape in the ebullition into the receiver. Not wishing to undertake a new distillation, I placed it in six vessels, and covered the mercury in each about the depth of an inch with diluted sulpluric acid. After five days of repeated and frequent agitation, having washed, dried, and passed it through paper, I found that it left no black stain on a delft plate, that its drops had no appendage or tail, and that it evinced a most brilliant surface, which did not tarnish during the space of several days that I kept it before applying it to use.

But whoever wishes by this process to purify mercury much amalgamated, should use sulphuric acid not diluted, in order to hasten the operation. In fact, having exposed mercury which had been used for what is called the revival of sheet-lead, and for the preparation of plain mirrors, to the action of this acid, in the space of some days it became equal in goodness to that which had undergone the preceding operation. The facts, however, which I have described, demonstrate that the above process is sufficiently useful in purifying mercury adulterated by other metals; and to confirm it, I was induced in May 1815 to resort to the following new experiments.

First. I inade by means of heat four amalgams of the following compounds. I. Two denari* of lead and two of bismuth with two ounces of mercury. 2. Four denari of lead with two ounces of mercury. 3. Four denaxi of tin with two ounces of mercury. 4. Two denari of lead and two of tin with two ounces of mercury. I then added to each of these six ounces of mercury.

Secondly. I put these amalgams, which had a dense and wrinkled pellicle on their surface, in so many bottles numbered with their respective numbers, and added concentrated sulphuric acid sufficient to cover each amalgam to the depth of two or three lines of a quarter of an inch. Afterwards by repeated agitation and changing the acid several times, I obtained in a greater or less number of days mercury, which I have, and which retained, after being kept many days, the most beautiful brightwess. The amalgam No. 2 was the first to yield pure mercury, the last was. No. 1 .

In this and in other experiments where I used concentrated sulphuric acid, I observed almost instantly around the amalgam a whitish, yellowish, or grayish powder, which always increased, and which I separated at the first washing, by putting into the bottle a new quantity of acid. With agitation the mercury divides into larger or smaller globules; not immediately, nor in a given time, but usually when it is somewhat purified. In the process more or less sulphurous acid is disengaged, and also sul-

* A denaro is the twenty-fourth part of an ounce.

phuretted 
phuretted hydrogen gas, which is not only sensible to the smell, but is proved by the test of paper moistened in a solution of acetate of lead; from which it appears that, besides the sulphuric acid being decomposed, the water with which it was united is also at the same time decomposed.

Lastly. By the same means I have separated mercury from the amalgam of mirrors*.

This experiment, which is pleasing in theory and principle, may even serve to demonstrate in the shortest period of time that, from sulphuric acid, sulphur may be extracted. In fact, putting in a two-ounce phial, for example, a quarter of an ounce (six denari) of the said amalgam, and adding concentrated sulphuric acid sufficient to cover it from one to two inches deep, and aiding the operation by shaking the bottle, that all the amalgam may mix with the acid, after a few minutes, particularly when the temperature of the atmosphere is not low, a most vivid ebullition takes place, accompanied by copious vapours, by the disengagement of much caloric, of sulphurous acid, of sulphuretted hydrogen gas, and also of sulpliur. The last remains attached to the neck of the bottle, and in the greater quantity the less the mouth of the bottle may be. Separating the residue, which is more or less whitish, by washing, the amalgam contained much less tin than at first; and submitting it again

$$
\text { many }
$$

* Van Engestrom to obtain the mercury from this amalgam proposed to distil it with powdered charcoal or with sulphur. Ann. de Chimie, xxvi. 293. [Note by the Translator.] Another experimental proof of the purity of the mercury thus retined, is the excellence of the thermometers made with it by the enlightened author's assistant $\uparrow$, with one of which I was presented at Pisa, and which I found exactly corresponding to a very good one made in London. In all the experiments which $I$ have made with these two thermometers, I bave not been able to discover, even with a magnifying glass, the least difference in their sensibility. Whether in the open air of the plains, on the Pisa mountains, in the vale of the Arno, the insalubrious furnace (in winter perhaps it may be called basin) of Florence, the heights of Feisole, the Apennines, the Pisa baths which are at the spring $100^{\circ}$, at that of Jove 94, and that of Ceres 93, or the baths of Lucca, which at the spring within the cave are $130^{\circ} .76$, at the hotbath $126^{\circ}, 8 c$.- the rise or fall of the mercury in both instruments was identically the same. The day on which I examined the Lucca baths, when the thermometers were exposed to the direct rays of the sun at the foot of the hill beneath the baths, and on the sheltered bank of the river, they rose in a very few minutes to $116^{\circ}$, and would have risen still higher had they been allowed more time. Both the Lucca and Pisa hot waters, like those of Bath, contain very little extraneous matter, much less than might be inferred from their high temperature and their respective situations near the base of lofty ridges of calcareous mountains : some depositions or incrustations of carbonate of lime appear at their source, but they contain very little gas and no iron. Dr. Franceschi, physician at the

Lucea

† In Savoy, Piedmont, and even Tuscany, persons who make barometer and thermometers are wholly unknown. 
many times to the same process, after having triturated it, and agitated it with the same acid, it first became fluid, afterwards divided into globules, and finally appeared purified mercury similar to that produced by the preceding experiments. Hence it appears that, by the action of sulphuric acid aided by the mechanical division effected by agitation, the adulterated nercury of commerce, and even that which contains a greater portion of extraneous motals, may be purified in a manuer sufficient to serve all the common purposes of experimental philosophy and chemistry. This method does not require continual attention, is not expensive, particularly where the nercury is little altered, and does not expose the operator to any danger.

\section{Ansuer to W. H. G.'s Observations on Mr. Tatum's} Experiments on Vegelation. By Mr. J. Tatum.

\section{To Mr. Tilloch.}

SIR, - Y our correspondent, W. H. G., in reply to the paper I communicated to your Magazine of July, accuses me of "6 unpardonable igiorance for pretending to enlighten one of the most controverted subjects of experimental science, by views and experiments which have been ditailed in half a dozen professed treatises, and otherwise pronulgated in every possible way."

Lucca batlss has published someaccount of them : but, as usual with writers on bat's, his work is more paneggrical and historical than chemical; - a much better account may be expected from his relative Dr. Domen. Yieri, professor of chemistry in the college of Lucca. A very satisfactory ard able analysis of the Pisa bath waters may aiso be expected from the modest and ingenious author of the preceling mernoir; who pirsues the discovery of facts with unremitting zeal, and leaves the development of crude theories to those self-called chemists whose pen, ink, and paper are more useful to them than acids, retorts, and furraces. There are still persons who ascribe these hot-baths to the infuence of volcanoes; but there is not the smallest trace of any thing like volcanic matter, or even any combustible substance, to be discovered within many miles of them; nothing that, either chemically o: geologically speaking, could sanction the belief that they owe their warmth to exhausted subterraneous volcanoes. Vast ridges of mountains surround them, entirely of carbonat of lime or hard and coarse marble, with occasionally veins of felspar, rock crystal, and very rarely traces of tourmaline; but very considerable intersections of these calcareous masses frequently orcur, consisting of various combinations of magnesia and lime, forming all the giadations from the hardest to the most friable schist. Gypsum and pyrites, particularly the former, are of rare occurrence, and never in such quantities as would sanction the conjecture that the caloric developed by the deconposition of the latter might contribute to raise the temperature of these springs. It is true that in the valleys adjoining these hot springs inflammable gas, chiefly carburetted hydrogen, abounds; but whether connected as a cause or an effect is not so easy to determine.

Vol. 50. No. 235. Nov. 1817. 